\title{
Ultrastructural alterations of human cortical capillary basement membrane in human brain oedema
}

\author{
Orlando José Castejón \\ Biological Research Institute, Faculty of Medicine, Zulia University, Maracaibo, Venezuela
}

\begin{abstract}
The capillary basement membranes are examined in severe traumatic brain injuries, vascular malformation, congenital hydrocephalus and brain tumours. They exhibit homogeneous and nodular thickening, vacuolization, rarefaction, reduplication, and deposition of collagen fibers. Their average thickness varied according to the aetiology and severity of brain oedema. In moderate brain oedema the thickness ranged from 71.97 to $191.90 \mathrm{~nm}$ in width, and in patients with severe brain oedema it varied from 206.66 to $404.22 \mathrm{~nm}$. The basement membrane complex appears apparently intact in moderate oedema, and shows glio-basal dissociation in severe oedema. In areas of highly increased cerebro-vascular permeability, the basement membrane shows matrix disorganization, reduplication, and bifurcations protruding toward the endothelial cells, and acting as abluminal transcapillary channels. In regions of total brain necrosis, its structural stability is lost showing loosening, dissolution and rupture. Basement membrane swelling is due to overhydration of its protein-complex glycoprotein matrix. The thickening, rarefaction and vacuolization are induced by the increased vacuolar and vesicular transendothelial transport. The degenerated basement membrane areas exhibit a finely granular precipitate interpreted as protein, proteoglycan, glycoprotein, and agrin degraded matrix.
\end{abstract}

Key words: basement membrane, brain oedema, electron microscopy.

\section{Introduction}

Brain oedema is an appropriate pathological condition for studying the fine ultrastructural alteration of capillary basement membrane [16]. This structure forms the second line permeability barrier of the anatomical and physiological blood-brain barrier [70]. In the animal central nervous system, the vascular basal lamina appears as a homogeneous structure with a density similar to that observed in glomerular lamina densa $[25,29]$. Numerous studies based on experimental and pathological conditions performed in several vertebrates, including man, have reported the following alterations of capillary basement membrane: thickening, rarefaction, vacuolization and reduplication $[4,6,12,17,23,24,28,30,32,34,47-49,54-56$, $58,60,61,67,78,79,83,91]$. Deposition of collagen in the basement membrane after arterial hypertension was reported by Garcia et al. [35], in rats after 10-minute cardiac arrest [87], in cerebral hypoperfusion considered as a risk factor for Alzheimer's disease [26], and after traumatic brain injury in the rat cerebral cortex [88]. Thickening of capillary endothelial cell basement 
membrane has been found as the most characteristic morphologic feature of diabetic microangiopathy $[12,42,50]$, in hypertension combined with diabetes [43], and in galactosaemic rats [31]. There also is thickening of the basement membrane covering a non-vascular cell of nerve, the perineural cells [41]. Thickening of the basement membrane of cortical capillaries has also been reported in Alzheimer's disease [57,59,68,69,72,74,93], scleroderma and Raynaud's disease [11], and in glomerular diseases [71]. In addition, age-related thickening of retinal capillary basement membrane was described earlier [64]. Berzin et al. [3] found that agrin is associated with heparan sulphate proteoglycans in the basement membrane, and that agrin and laminin fragmentation occurs in Alzheimer's disease. Inoue [39] and Inoue and Kisilevski [40] reported abundant microfibril-like $\beta$-amyloid in the basement membrane in the cerebrovascular amyloid angiopathy of Alzheimer's disease. Sehba et al. [75] demonstrated an acute loss of collagen IV from the cerebral microvasculature after aneurysmal subarachnoid haemorrhage.

Plesea et al. [67] found focal or circumferential capillary thickening due to densification of the type IV collagen material from the basement membrane structure in hypertensive cerebral haemorrhage. Schóller et al. [76] demonstrated basal lamina damage correlated with blood-brain barrier dysfunction following subarachnoid haemorrhage in rats. According to Wang et al. [86], damage to the basal lamina causes the dismantlement of microvascular wall structures, which in turn results in the increase of microvascular permeability, haemorrhagic transformation, brain oedema and compromise of the microcirculation. In animal models, ischaemia reperfusion (IR) injury triggers membrane lipid degradation and accumulation of lipoxidative exacerbations in the neurovascular unit, leading to blood-brain barrier damage and neurologic deficits [38]. Uranova et al. [81] found ultrastructural abnormalities of capillaries in schizophrenia included thickening and deformation of basal lamina. String vessels or collapsed empty basement membrane tubes devoid of endothelial cells, and considered acellular capillaries, are often associated with pathologies such as Alzheimer's disease, ischaemia, and irradiation, but are also found in normal human brains from preterm babies to the aged. This causes an age-related decline in cerebral angiogenesis and results in neuronal loss. These string capillaries can re-grow by proliferation and migration of endothelial cells into empty basement membrane tubes, which provide a structural scaffold, replete with signalling molecules [7]. Castejón [21] showed thin and fragmented basement membranes with areas of focal thickening in human congenital hydrocephalus. Castejón [22] also reported that hypertrophic pericytes induce basement membrane splitting in traumatic brain oedema.

The purpose of this review is to describe the alterations of capillary basement membrane in vascular anomaly, brain trauma, congenital hydrocephalus, and brain tumours. The following aspects are summarized: the basement membrane complex in an apparently normal basement membrane, the basement membrane thickness according to aetiology, degree of brain oedema, and age of the patients; the alterations of the basement membrane complex and the pathogenesis of glio-basal dissociation, and the transbasal membrane pathway for haematogenous oedema fluid. In addition, we have postulated a neurobiological interpretation of thickening, rarefaction and vacuolization of the basement membrane in the light of present knowledge on chemical composition of basement membrane, pathogenesis of vasogenic brain oedema, and the increased transendothelial vacuolar and vesicular transport. It is also important to make an evaluation of the structural stability of basement membrane in severe oedema and perivascular total brain necrosis, and to discuss the proliferation of collagen fibers into the basement membrane.

\section{The normal capillary basement membrane}

In human brain capillaries as observed in moderate oedematous regions of cortical biopsies of patients with vascular anomalies and congenital hydrocephalus, the basement membrane appears as a homogeneous, thin and continuous dense lamina due to its condensed filamentous pattern, embedded in a homogeneous matrix (Fig. 1).

Basal lamina splitting occurs in apparently normal areas, in which the cell body and the pericyte processes can be seen enclosed within the basal lamina compartments. This apparently normal capillary basement membrane closely resembles that observed in normal vertebrate $[1,8,25,73]$, and invertebrate tissue [2]. In humans and in experimental animals, the basement membrane thickness varies from capillary to capillary, and even locally within a single 


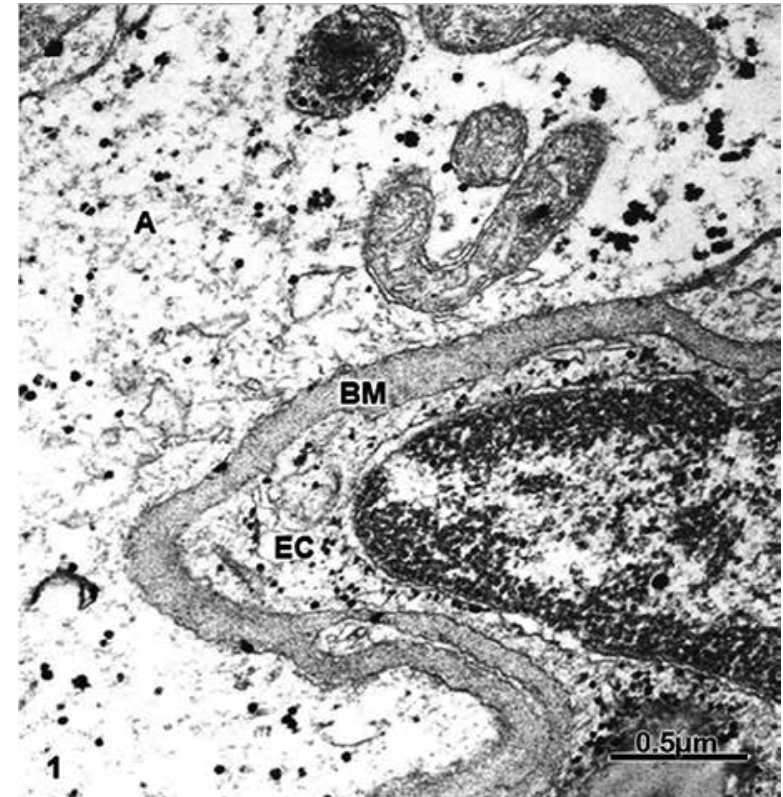

Fig. 1. Anomaly of the anterior cerebral artery. Right parietal cortex. Capillary from a moderate oedematous region showing an apparently normal basement membrane (BM) exhibiting a homogeneous dense matrix. The endothelial cell (EC) and the swollen astrocytic glial endfoot (A) plasma membranes are closely applied to the basement membrane luminal and abluminal surfaces.

capillary [73]. Furthermore, the average thickness seems to increase with the aging process $[46,64]$. According to Laursen and Diemer [49], the harmonic mean basement membrane thickness of normal cortical capillaries of male Wistar rats is $52.37 \mathrm{~nm}$ in width.

\section{Basement membrane thickening in moderate and severe traumatic brain oedema}

In patients with traumatic brain injuries, examination of moderately oedematous regions show capillaries apparently not activated by the traumatic agent. In such regions, the apparently normal capillary basement membrane width ranges from 71.97 to $191.90 \mathrm{~nm}$ [19] (Fig. 2).

In patients with severe traumatic brain oedema the capillary basement membrane appear thickened. The basement membrane width ranges from 206.66 to $404.22 \mathrm{~nm}$ [19]. In addition, the basement membrane appears vacuolated (Fig. 3).

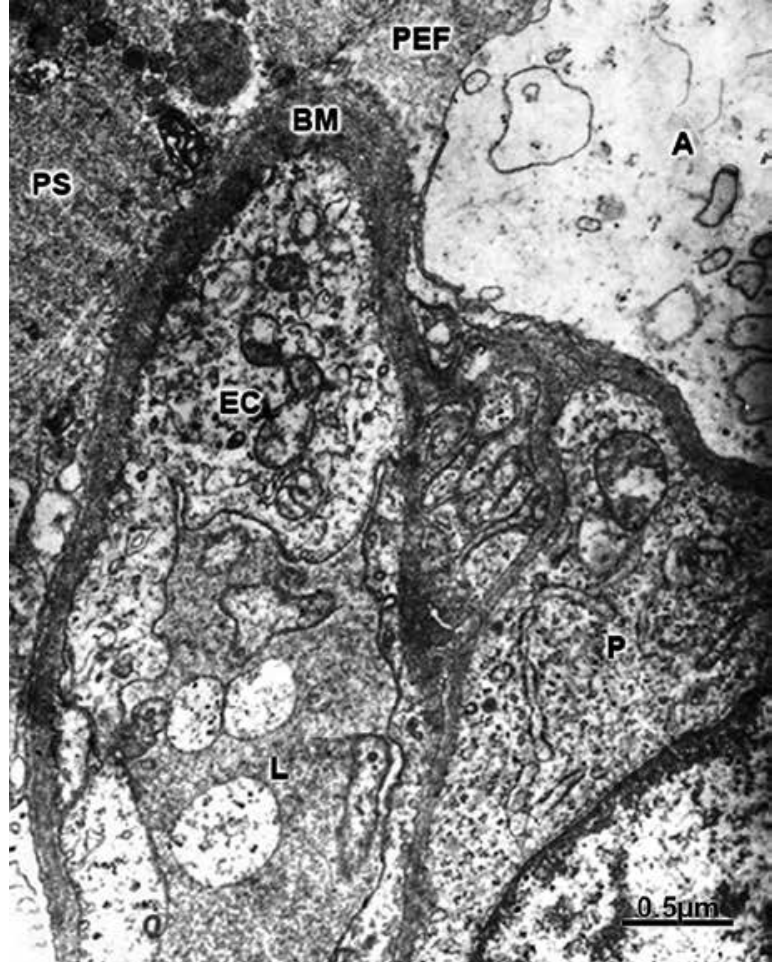

Fig. 2. Brain trauma. Right epidural haematoma. Right temporal cortex. Compact and dense capillary basement membrane (BM) showing an apparently normal structure in a moderate oedematous region. On the contrary, the clear perivascular astrocytic end-foot (A) shows a marked oedema. The pericytal cytoplasm (P) enclosed within the basement branches, the activated endothelial cell (EC), and the capillary lumen (L) are also seen. Note the presence of proteinaceous oedema fluid (PEF) in the perivascular space (PS).

\section{Capillary basement membrane vacuolization}

In patients with severe brain traumatic injuries, and loss of consciousness after alcohol ingestion, in addition to the increased vesicular and vacuolar transendothelial transport, a thickened and vacuolated basement membrane is found $[14,16]$. The mechanisms of increased extravasation of macromolecules across the blood-brain barrier exerted by ethanol intoxication are obscure. Theoretically, changes in vascular tones, vascular perfusion, as well as interference with blood coagulation, endothelial biogenic amine metabolism, and endothelial plasmalemma, all might contribute to this increased extravasation [66]. 
Endothelial vacuoles are observed discharging their content directly into the basement membrane or by means of plasmalemmal vesicles. Clathrin-coated and uncoated vesicles have also been found connected to the basement membrane surface $[14,16]$ at the endothelial and pericytal margins. This increased vacuolar and vesicular transport induces progressive and slow alteration of the basement membrane matrix resulting in a gradual process of hydration, thickening, rarefaction, vacuolization and structural matrix disorganization. From the damaged basement, the oedema fluid penetrates into the astrocytic perivascular end-feet processes via the astrocyte cell soma [82]. The basement membrane vacuolization observed in very severe oedematous areas and in regions of brain parenchyma destruction reveals a complete loss of its diffusion-barrier function. A simultaneous vacuolization of endothelial cells, pericytes, astrocytes, and open endothelial junctions $[17,23]$ was also encountered as the morphological substrate of enhanced transcapillary protein transport [14].

If endothelial cells, pericytes and perhaps glial cells participate in the elaboration of the normal basement membrane [25], the reverse process: the degeneration of these cells could induce basement membrane degradation and lysis. Basement membrane thickening and vacuolation also were observed by Kamyrio et al. [44] after gamma knife irradiation. In addition, Li et al. [51] have reported basement thickening in rats after simulated weightlessness.

In patients with head trauma and blood hypertension, the possibility exists that, in addition to the brain oedema, degenerative changes of capillary basement membrane should be present, as part of the degenerative changes of smaller penetrating cerebral vessels. The development of severe oedema in this case could be due in part to permeability changes to protein in penetrating vessels [27].

In several models of animal and human brain oedema, in which enhanced permeability to protein exists, loosening and swelling of the basement membrane have been earlier described $[28,48,58,60,76,78]$.

In earlier studies $[14,16,19]$, we have shown increased vesicular and vacuolar endothelial transport in cortical capillaries of patients with brain trauma, brain tumours, and congenital malformations. These morphological features of increased capillary permeability are closely related with the basement membrane thickening [19]. Basement membrane thicken-

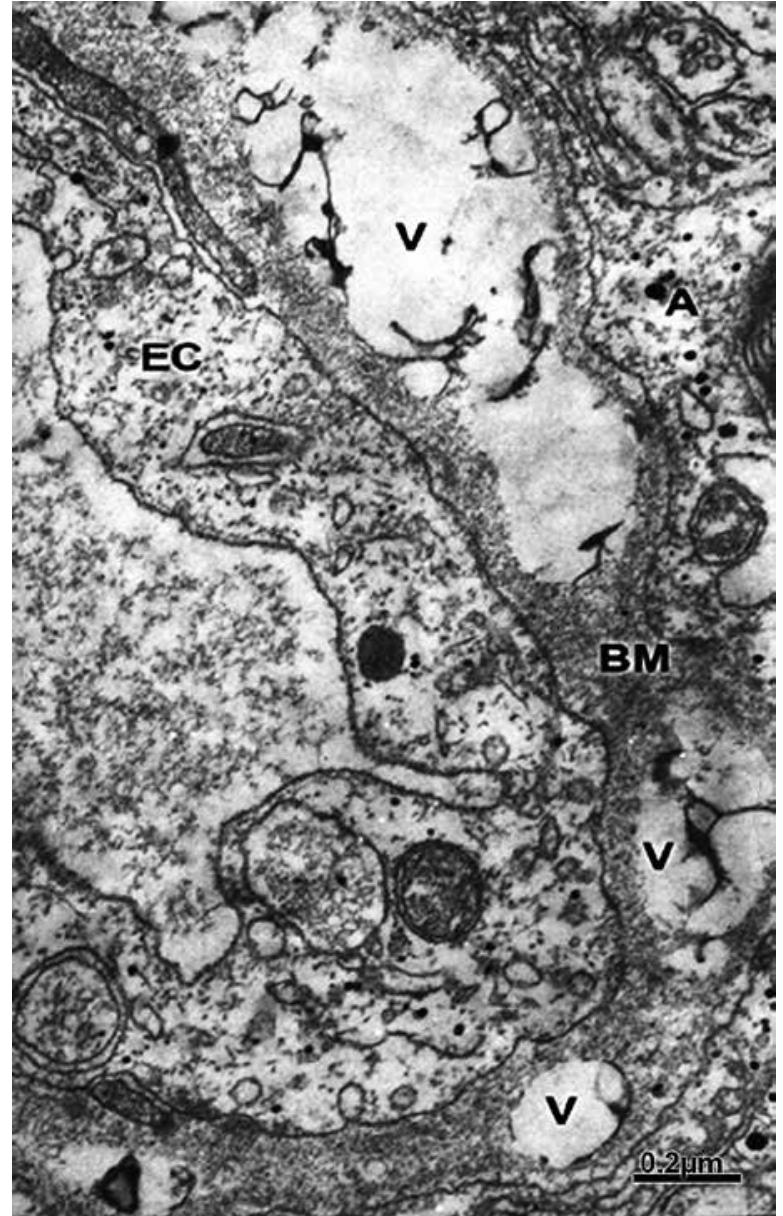

Fig. 3. Brain trauma. Right parieto-temporal subdural haematoma. Right parietal cortex. Thickened and vacuolated (V) basement membrane (BM) of a capillary localized in a severely oedematous area. The swollen and vacuolated endothelial cell (EC) and astrocytic end-foot (A) are also observed.

ing has also been reported in different non-nervous pathological entities. Laursen and Diemer [49] reported an increase in the thickness of the brain capillary basement membrane after 30 days of portocaval anastomosis. Enlargement of the basement membrane has been described myxedema and polymyositis [84]. Basement membrane thickening in diabetes is also associated with increased capillary permeability which becomes manifest when the duration of diabetes exceeds 10 years [59]. According to these authors, the ischaemia could be a contributing factor to the basement membrane thickening. Basement membrane changes seem to be more a result than the cause of increased capillary 
permeability. In addition, it has been reported that hypoxia causes oedema and disruption of endothelial basement membrane in pulmonary arteries [62]. Increased basement membrane thickness of skeletal muscle capillary in congestive heart failure has been reported by Longhurst et al. [54]. In congestive heart failure a high degree of local hypoxia undoubtedly occurs especially during exercise. According to these authors, an increased basement membrane thickness may be a result of local hypoxia and cell death. With the formation of new cell components, the new basement membrane material may oppose itself to the old lamina leading to significant thickening.

In an experimental model of brain oedema, such as cold injury oedema, one of the most commonly used model for traumatic vasogenic oedema [52], rarefaction and widening of the capillary basement membrane occur almost before any other vascular change. Thickening of the basement membrane has been also reported in the vasogenic brain oedema induced by intraventricular collagenase infusion [36]. The collagenase induces blood-brain barrier impair-

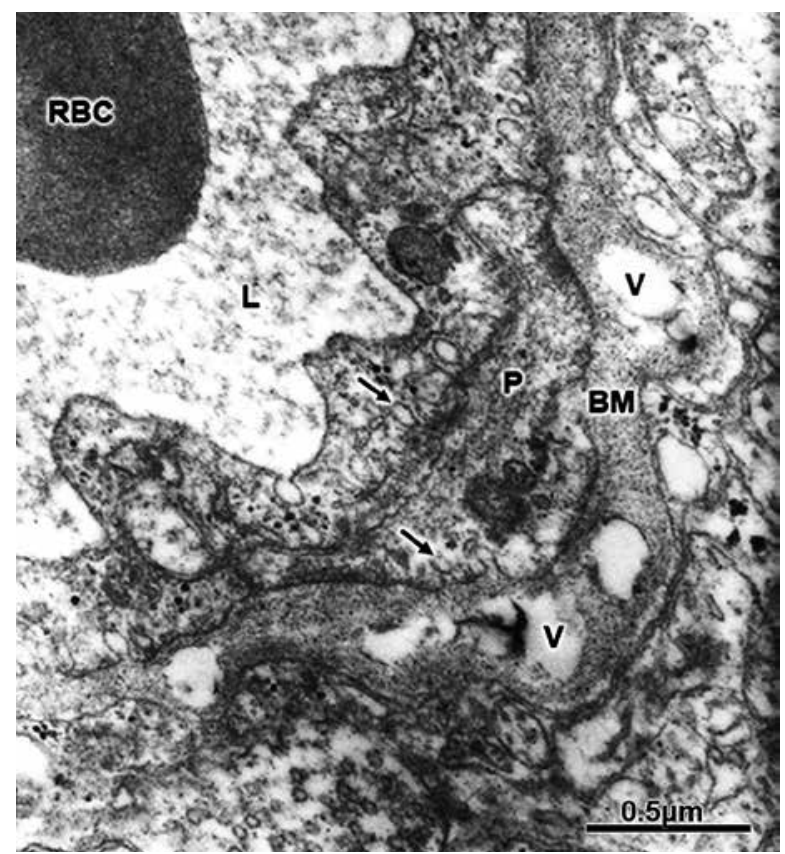

Fig. 4. Anomaly of the anterior cerebral artery. Right parietal cortex. Severe oedema. Swollen and vacuolized (V) capillary basement membrane (BM). Increased pinocytotic activity is observed in the endothelial cell and pericytal cytoplasm (P) (arrows). The capillary lumen (L) and a red blood cell (RBC) are also distinguished. ment by its action on the vascular basement membrane, not altering the structures in the brain parenchyma, and causing oedema formation and protein extravasation. Thickened capillary basement membrane is also reported in arterial hypertension [35], and diabetes [42]. Hypertension combined with diabetes also enhance basement thickening [43]. Similar findings are observed in galactosaemic rats [31], and in streptozotocin-induced diabetes [6].

Capillary basement membrane thickening in Alzheimer's disease has been widely reported by several workers $[68,69,74,93]$. Berzin et al. [3] and Salloway et al. [72] have implicated agrin, a synaptic organizing protein, in basement membrane damage in Alzheimer's disease.

\section{Swollen and vacuolized capillary basement membrane in vascular anomaly and congenital hydrocephalus}

In congenital malformations, such as vascular anomalies and congenital hydrocephalus, basement membrane thickening and vacuolization is also observed (Figs. 4 and 5).

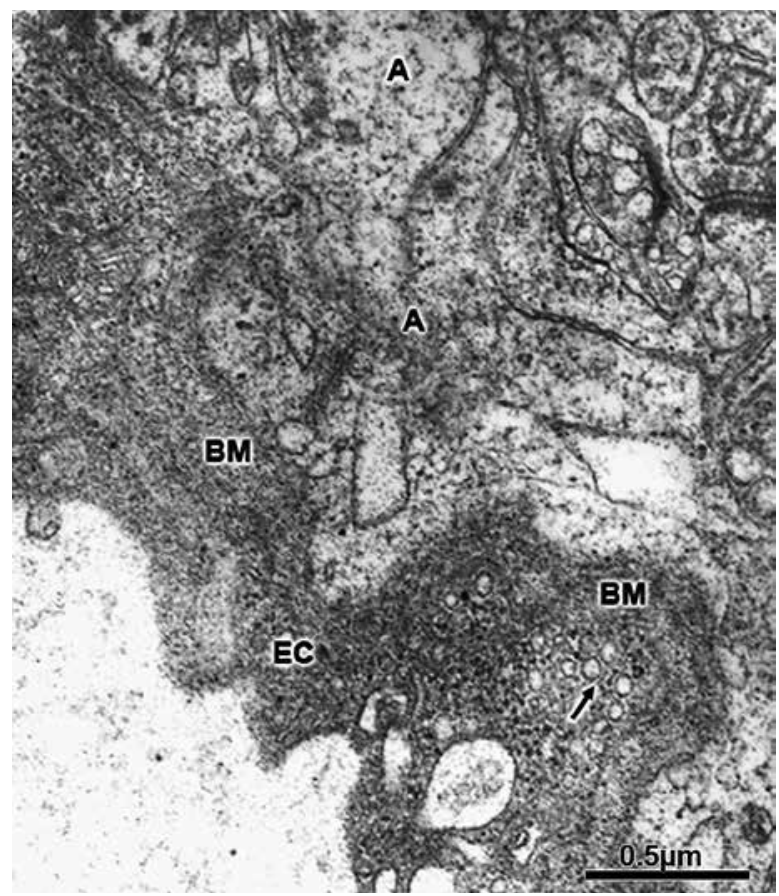

Fig. 5. Congenital hydrocephalus. Right parietal cortex. A swollen, undulated and immature capillary basement membrane (BM) is observed. Note the increased pinocytotic activity (arrow) in the dark endothelial cell (EC), and the swollen perivascular astrocytic end-feet (A). 


\section{Capillary basement membrane thickening in brain tumours}

In brain tumours the capillary basement membrane also appears notably swollen, rarefacted, and exhibiting a dark and finely granular precipitate (Fig. 6).

Immunohistochemical expression of laminin 1 and 2 has been found in brain tumour vessels [80] and in breast cancer [33]. A redistribution of aquaporin-4 channels and loss of agrin has been observed by Warth et al. [90] in human glioblastoma.

\section{Basement membrane bifurcations acting as abluminal channels}

The basement membrane bifurcations enclosing the pericyte processes appear as irregularly dilated translucid channels, following a contoured course, approaching to the luminal endothelial plasma membrane $[13,22]$. These expansions originate from the basement membrane and after a short trajectory applied to the endothelial cytoplasm, converge again onto the basement membrane. These expansions lost their matrices

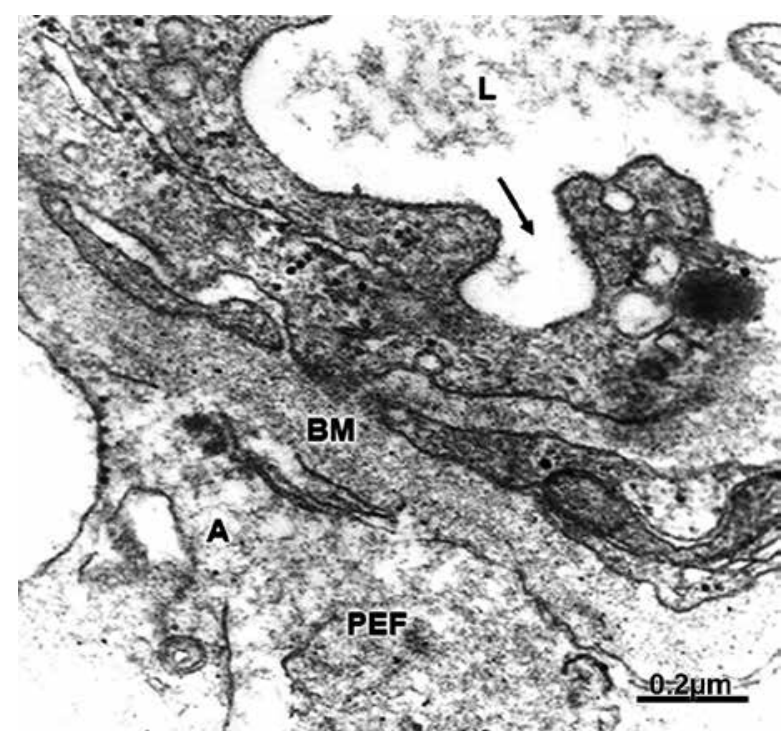

Fig. 6. Cystic craniopharyngioma. Right frontal cortex. Swollen capillary basement membrane (BM) exhibiting rarefaction and a fine and dark granular precipitate. Note the proteinaceous oedema fluid (PEF) in the perivascular astrocytic end-foot (A) similar to that observed in the capillary lumen (L). The endothelial cell shows deep invaginations (arrow) of the luminal surface to form protein containing vacuoles. in large segments, and appear as dilated electronlucid channels, resulting from increased capillary permeability (Fig. 7).

The swollen capillary basement membrane branches seem to function as abluminally oriented transcapillary channels for massive escape of haematogenous oedema fluid. These dilated basement membrane branches have been interpreted as basement membrane modifications in response to heightened transcapillary exchange in traumatic brain oedema [19]. Such structures, together with transendothelial, pericytal and astrocytic channels $[15,17,19,23]$ seem to represent the basic morphological substrate for massive escape of hematogenous oedema fluid in vasogenic brain oedema.

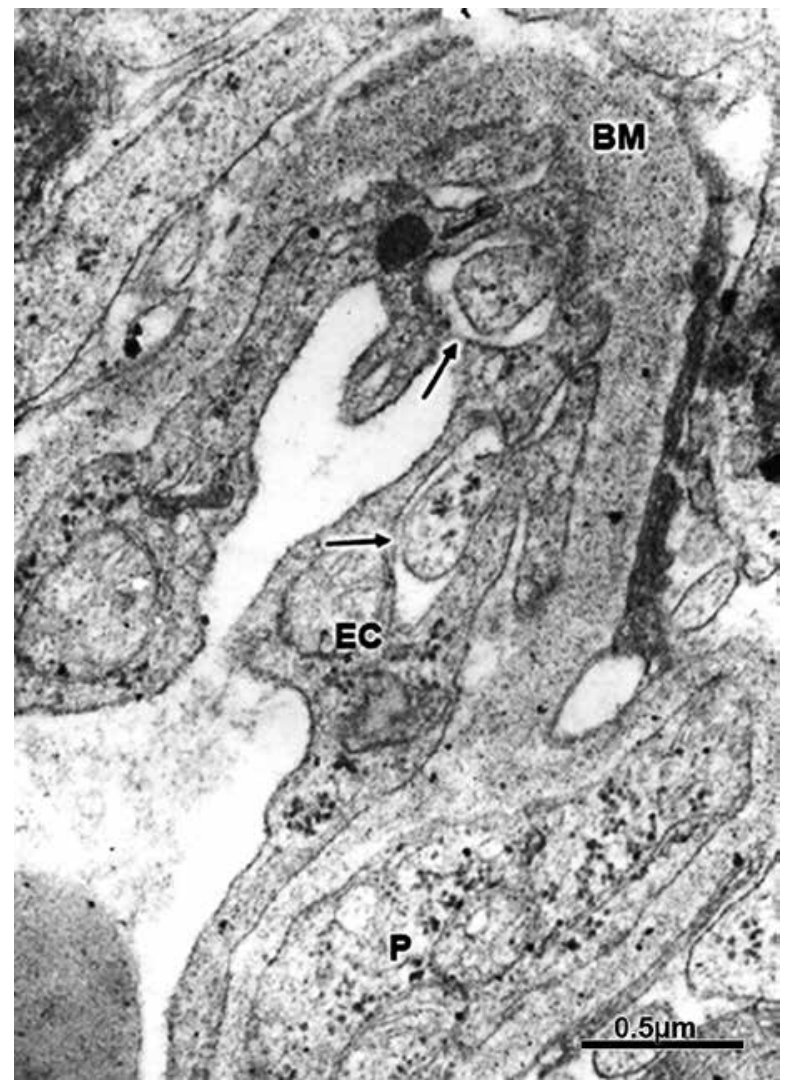

Fig. 7. Brain trauma. Contusion and fracture of the frontal region. Left frontal cortex. Dilated and contorted basement membrane branches (arrows) approaching to the endothelial cell (EC), and acting as abluminal transcapillary channels. Note the continuity with the swollen basement membrane (BM). P labels the enclosed pericytal cytoplasm (P) within the basement membrane. 


\section{The glio-basal dissociation process}

In some severe brain oedema areas, the astrocytic end-feet limiting membrane appears slightly detached from the basement membrane outer surface and follow an undulated trajectory. In these areas, the astrocytic glial end-feet are extremely swollen and glial filaments are frequently absent. The lack of attached glial filaments probably induced the glio-basal dissociation process [19] (Fig. 8).

Astrocytic invaginations precede the formation of astrocytic vacuoles, by means of which the oedema fluid seems to be transported to the neighbouring neuropil $[16,82]$. Apparently in the severe oedema, the swollen and fragmented astrocytic processes release the already up-taken haematogenous oedema fluid in the neighbouring enlarged extracellular space which, in turn, dissects the astrocytic membrane from the basement membrane complex [19]. In areas of total brain tissue necrosis due to traumatic alteration of the bloodbrain barrier, evinced by presence of extravasated erythrocytes, a severe alteration of basement membrane is observed consisting of loosening up and dissolution of its matrix.

As illustrated in Fig. 9, the denuded basement membrane tends to loosen up and shows evidence

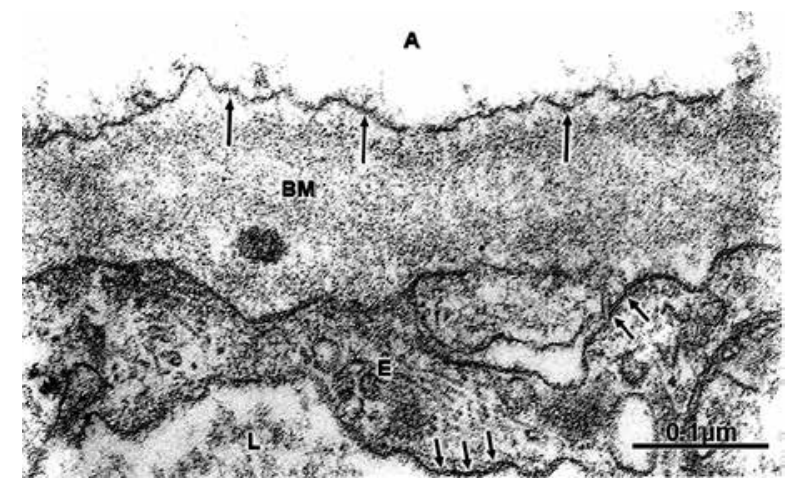

Fig. 8. Brain trauma. Left parieto-occipital subdural hygroma. Capillary of left parietal cortex. The thickened basement membrane (BM) exhibits matrix rarefaction and a finely granular appearance, corresponding to uranyl and lead staining of the swollen and degenerated basement membrane matrix. The luminal and abluminal endothelial (E) membranes are structurally intact (short arrows). The astrocytic end-foot (A) membrane follows an undulated course (long arrows) and the glio-basal dissociation process is initiated. The capillary lumen is labelled with an $\mathrm{L}$. of the actual rupture not preventing the spreading of perivascular haemorrhages.

After a long evolution time of a brain trauma, the basement membrane and the perivascular glia still persist, demonstrating that these structures are the most resistant barrier elements of the vessel walls. This fact indicates the high structural stability of basement membrane in relationship to endothelial cells, pericytes and astrocytic end-feet, as it has been previously pointed out by Blinzinger et al. [5] in areas of cold-induced total cortical necrosis.

\section{Proliferation of collagen fibers in the basement membrane}

In some cases, the thickened basement membrane exhibits proliferation of collagen fibers (Fig. 10).

Proliferation of collagen fibers has also been reported by Long et al. [53] in malignant brain tumours, and by Calhoun and Mottaz [10] in experimental cerebral infarction. Nevertheless, these authors reported the presence of fibroblast in the pericapillary space. Although chemical evidence of a collagenous protein exists in the basement membrane [77], electron microscopy has not demonstrated collagen fibrils in the normal brain capillary basal lami-

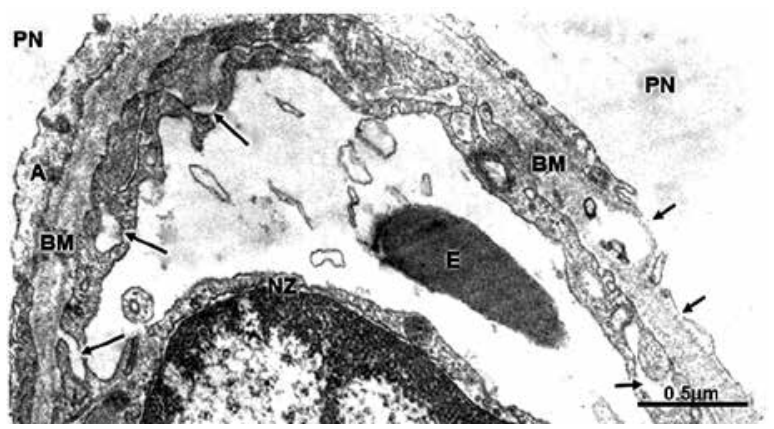

Fig. 9. Brain trauma. Subdural hygroma. Left parietal cortex. Capillary located in area of brain tissue necrosis showing a denuded and vacuolated (short arrows) basement membrane (BM). A thin layer of perivascular astrocytic end-foot (A) is still appreciated. The long arrows indicate swollen basement branches invaginating the endothelial cytoplasm, and acting as abluminal channels. Note the absence of perivascular neuropil (PN), the prominent endothelial nuclear zone (NZ), and a partial view of an intraluminal erythrocyte (E). 


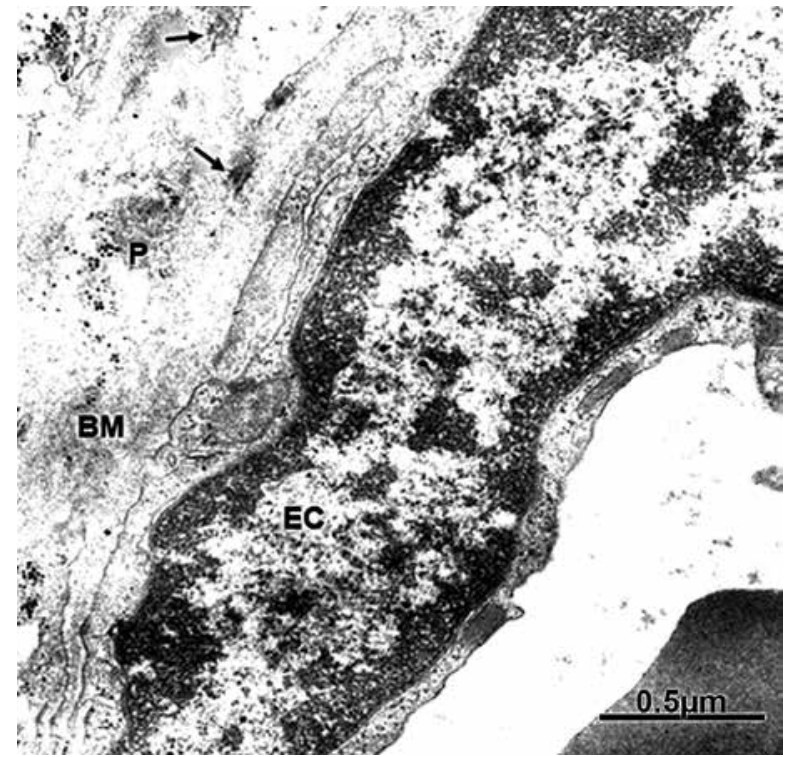

Fig. 10. Meningioma of the frontal cortex. Capillary of the right frontal cortex. Proliferations of collagen fibers (arrows) are observed within the basement membrane (BM) surrounding the pericytal cytoplasm $(P)$. The endothelial cell (EC) is also seen.

na [25]. Proliferation of collagen fibers at the level of the basement membrane coexists with the presence of dark neuroglial cells, apparently pericytal microglia [63] attached to its outer surface, replacing the astrocytic pericapillary layer. We infer that pericytal microglia acquire fibroblastic properties and elaborate collagen properties, as an adventitial reaction. If, as considered by Bar and Wolff [1], the basement membrane plays a role in regulating the differentiation of adjacent neuroglial cells, it seems plausible that the capillary basement membrane could regulate the differentiation of this neighbouring pericytal microglia. It is also possible that this cell participates in the formation and maintenance of the reduplicated basement membrane. Collagen fibrils have been found beneath the basement membrane by García et al. [35] after arterial hypertension, by Walski et al. [87], and Walski and Gajkovska [88] after traumatic brain injury in rat cerebral cortex, and within the basement membrane in aged rats [26]. $\beta$-amyloid fibrils have been described in the capillary basement membrane in Alzheimer's disease [39,40]. Plesea et al. [67] encountered densification of the type IV collagen material in the basement membrane of cerebral vasculature in hypertensive intracerebral haemorrhage.

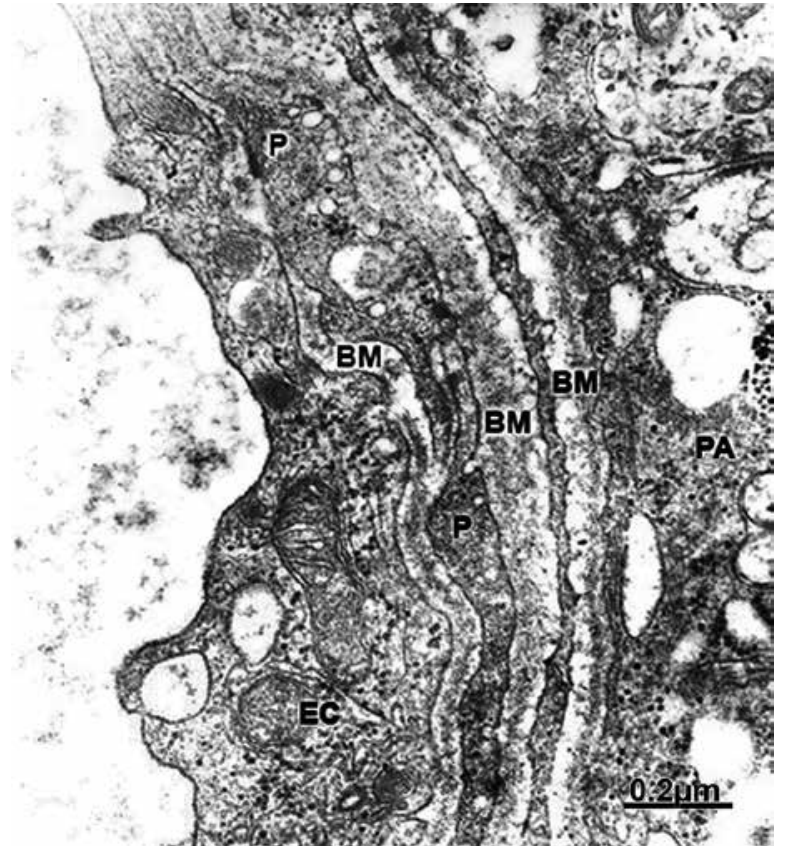

Fig. 11. Brain trauma. Right parieto-temporal subdural hematoma. Left parietal cortex. Cortical capillary showing reduplicated basement membranes (BM) which appear separated by thin bands of pericytal cytoplasm (P). The vacuolated endothelial cell (EC), and dark perivascular astrocytic end-foot (PA) are also seen.

\section{Reduplication of capillary basement membrane}

Reduplicated capillary basement membranes have been also found in our patients with brain oedema associated to brain trauma and tumours (Fig. 11).

Reduplicated capillary basement membrane has been earlier reported by Luse and McDougal [55] in allergic encephalomyelitis; by Kiser and Kending [47] in the capsule of cerebral abscesses, by Ward et al. [89], Ferrer and Lopez-Pousa [30], and McLone [61] in brain tumours. According to Vracko and Benditt [84], the accumulation and lamellation of basement membrane would be a result of repeated episodes of cell death and regeneration. Therefore, Vracko [85] considers that layering, splitting or lamination of basement membrane is due to cell death and cell replenishment. The individual layer has been deposited there by new cell generation and gives an indication of the number of cell generations which have occurred at that particular site. The reduplication of the basement membrane could also be 
a phenomenon induced by pericyte cell hypertrophy [15]. A multilayered basement membrane has been described by Yoshida et al. [92] in the repair process of cerebral infarction in rats, in subarachnoid haemorrhage [56], and in capillary vessels of neurohypophysis after focal ischaemia of cerebral cortex [32].

\section{Basement membrane thickening and the aging process}

We have studied a group of patients with congenital hydrocephalus whose age ranges from several months up to ten years, which exhibit focal swelling of basement membrane [18,21], and in patients with traumatic head injuries up to 80 years of age [20]. We have tried to establish a correlation between the age of the patient and the basement membrane width, in order to elucidate if, besides the pathological basement membrane thickening associated to brain oedema, there is also an increase in basement membrane thickness due to the aging process, as earlier suggested by Kilo et al. [46], and Nagata [64]. An increased basement membrane thickness is found up until 60 years of age. However further changes were not detected between 60 and 80 years [19]. Bruns et al. [9] have earlier reported an increased basement membrane thickness of cortical capillaries with increasing age in the cerebral cortex of the aging primate, Macaca nemestrina. The authors reported an increased basement membrane thickness between 4 and 10 years, but no further changes between 10 and 20 years. According to these authors, a regression analysis revealed no significant increase in thickness of the basement membrane with increasing age. In our study we have considered that only $45 \%$ of the variability of basement membrane width is due to the aging process, and the remaining $55 \%$ of the variability is related to the associated brain oedema [19]. A further study should be done in normal old subjects to really evaluate the possible changes of basement membrane thickness during aging. This study is obviously limited for ethical reasons in the normal human central nervous system.

\section{A neurobiological interpretation of capillary basement thickening}

We have considered the basement membrane enlargement in brain oedema as an unspecific reaction due to overhydration of its protein polysaccharide matrix. According to Hall [37] and Spiro
[77], the basement membrane can be conceived as a network of collagen molecules having positive charges, surrounded by negatively charged mucopolysaccharides. According to Pease [65] in the presence of water, polysaccharides occupy large areas or domains compared to the weight of the molecule and not only water may penetrate these polysaccharide domains, but ions and small molecules. Berzin et al. [3] demonstrated that agrin is associated with heparan sulphate proteoglycans in the basement membrane. These biochemical data could explain the basement membrane thickening in human brain oedema. As we have previously postulated $[16,19]$, the increased transcapillary passage of ions and water in brain oedema would produce a high state of hydration of the basement membrane matrix. Since the fundamental alteration in vasogenic brain oedema is an increased transcapillary transfer of fluids, ions, proteins and small molecules, we infer that the enlargement of the basement membrane can be initially considered as a state of overhydration of its protein - polysaccharide matrix or anionic sites. Consequently a notable loss of the role of the basement membrane as a semipermeable filter [45] or permeability-barrier function occurs in brain oedema. A discontinuity in the distribution of anionic sites can be associated with an increased capillary permeability, as observed in scrapie-infected mice [83].

Through the effect of cerebral oedema, collagen or proteins similar to collagen, proteoglycans and glycoproteins of the basement membrane are degraded, presumably producing a selective precipitation of uranyl and lead salts in these areas, as observed in the transmission electron microscopic images stained by these electron staining techniques [19]. Fragmentation of agrin, a synaptic organizing protein, found in the basement membrane $[3,72]$ could also be implicated as the molecular substrate for basement membrane granularity.

\section{Concluding remarks}

The capillary basement membranes are examined in severe traumatic brain injuries, vascular malformation, congenital hydrocephalus and brain tumours. The capillary basement membrane exhibits homogeneous and nodular thickening, vacuolization, rarefaction, reduplication, and deposition of collagen fibers. Their average thickness varied according to the aetiology and severity of brain oedema. In 
moderate brain oedema the thickness ranged from 71.97 to $191.90 \mathrm{~nm}$ in width, and in patients with severe brain oedema it varied from 206.66 to 404.22 $\mathrm{nm}$. The basement membrane complex appears apparently intact in moderate oedema and shows glio-basal dissociation in severe oedema. In areas of highly increased cerebro-vascular permeability, the basement membrane shows matrix disorganization, reduplication, and bifurcations protruding toward the endothelial cells, and acting as abluminal transcapillary channels. In regions of total brain necrosis, its structural stability is lost showing loosening, dissolution and rupture. Basement membrane swelling is due to an overhydration of its protein-complex glycoprotein matrix. The thickening, rarefaction and vacuolization are induced by the increased vacuolar and vesicular transendothelial transport. The degenerated basement membrane areas exhibit a finely granular precipitate interpreted as protein, proteoglycan, glycoprotein, and agrin degraded matrix.

\section{References}

1. Bär T, Wolff JR. The formation of capillary basement membranes during internal vascularization of the rat's cerebral cortex. Z Zellforsch Mikrosk Anat 1972; 133: 231-248.

2. Barber VC, Graziadei P. The fine structure of cephalopod blood vessels. I. Some smaller peripheral vessels. Z Zellforsch Mikrosk Anat 1965; 66: 765-781.

3. Berzin TM, Zipser BD, Rafii MS, Kuo-Leblanc V, Yancopoulos GD, Glass DJ, Fallon JR, Stopa EG. Agrin and microvasclar damage in Alzheimer's disease. Neurobiol Aging 2000; 21: 349-355.

4. Bi L, Li YX, He M, Huang ZM, Zhao DS, Lan JQ. Ultrastructural changes in cerebral cortex and cerebellar cortex of rats under simulated weightlessness. Space Med Med Eng 2004; 17 180-183.

5. Blizinger K, Matsushima A, Anzil AP. High structural stability of vascular and glial basement membranes in areas of total brain tissue necrosis. Experientia 1969; 15: 976-977.

6. Bouchard P, Ghitescu LD, Bendayan M. Morpho-functional studies of the blood-brain barrier in streptozotocin-induced diabetic rats. Diabetologia 2002; 45: 1017-1025.

7. Brown WR. A review of string vessels or collapsed, empty basement membrane tubes. J Alzheimers Dis 2010; 21: 725-739.

8. Bruns RR, Palade GE. Studies on blood capillaries. I. General organization of blood capillaries in muscle. J Cell Biol 1968; 37: 244-276.

9. Bruns EM, Kruckeberg MS, Comerford LE, Buschmann MBT. Thinning of capillary walls and declining numbers of endothelial mitochondria in the cerebral cortex of the aging primate, Macaca Nemestrina. J Gerontol 1979; 34: 642-650.

10. Calhoun CC, Mottaz JA. Capillary bed of rat cerebral cortex. The fine structure in experimental cerebral infarction. Arch Neurol 1966; 15: 320-328.
11. Camilleri JP. Fine structural capillary changes and basal lamina thickening in scleroderma (progressive systemic sclerosis) and Raynaud's disease. Pathol Res Pract 1984; 178: 230-236.

12. Carson KA, Hanker JS. Basal lamina thickness and permeability to horseradish peroxidase of intraneural capillaries in diabetic mice. Microvasc Res 1980; 20: 223-232.

13. Castejón OJ. Formation of transendothelial channels in traumatic human edema. Pathol Res Pract 1984a; 179: 7-12.

14. Castejón OJ. Increased vesicular and vacuolar transport in traumatic human brain edema. A combined electron microscopy and theoretical approach. J Submicrosc Cytol 1984b; 16: 359-369.

15. Castejón OJ. Submicroscopic changes of cortical capillary pericytes in human perifocal brain edema. I Submicrosc Cytol 1984c; 16: 601-618.

16. Castejón OJ. Electron microscopic study of capillary wall in human cerebral edema. J Neuropathol. Exp Neurol 1980; 39: 296-328.

17. Castejón OJ. Electron microscopic observations of endothelial junctions in perifocal human brain edema. An interpretative study. J Submicrosc Cytol 1985; 17: 105-114.

18. Castejón OJ. Transmission electron microscope study of human hydrocephalic cerebral cortex. I Submicrosc Cytol Pathol 1994; 26: 29-39.

19. Castejón OJ. Ultrastructural alteration of human cortical capillary basement membrane in perifocal brain edema. J Submicrosc Cytol Pathol 1988; 20: 519-536.

20. Castejón OJ, Castejón HV, Diaz M, Castellano A. Consecutive light microscopy, scanning-transmission electron microscopy and transmission electron microscopy of traumatic human brain oedema and ischaemic brain damage. Histol Histopathol 2001; 16: 1117-1134.

21. Castejón OJ. Submicroscopic pathology of human and experimental hydrocephalic cerebral cortex. Folia Neuropathol 2010; 48: 159-174.

22. Castejón OJ. Ultrastructural pathology of cortical capillary pericytes in human traumatic brain oedema. Folia Neuropathol 2011; 49: 162-173.

23. Castejón OJ. Ultrastructural pathology of endothelial tight junctions in human brain oedema. Folia Neuropathol 2012; 50: 118129.

24. Cervós-Navarro J. Brain edema due to ionizing radiation. In: Klatzo Y, Seitelberger F (eds.). Brain Edema Springer-Verlag, New York 1967; pp. 632-638.

25. Delorme P, Grignon G. An autoradiographic study on the biosynthesis of the capillary basal lamina in the chick embryo telencephalon. Cell Tissue Res 1978; 192: 299-308.

26. De Jong GI, De Vos RA, Steur EN, Luiten PG. Cerebrovascular hypoperfusion: a risk factor for Alzheimer's disease? Animal model and postmortem human studies. Ann N Y Acad Sci 1997; 26: 826-856.

27. Dinsdale HB. Hypertension and the blood-brain barrier. In: Cervos-Navarro J, Betz E, Ebhardt G, Ferst R, Wullemweber R (eds.). Advances in Neurology. Vol. 20. Raven Press, New York 1978; pp. 341-346.

28. Donahue S, Zeman W, Watanabe L. Alterations of basement membrane of cerebral capillaries. I Neuropathol Exp Neurol 1967; 26: 397-411. 
29. Donahue J, Pappas GD. The fine structure of capillaries in the cerebral cortex of the rat at various stages of development. Am J Anat 1961; 108: 331-347.

30. Ferrer I, Lopez-Pousa S. Microvascularizacion de tumores cerebrales. Un estudio con bencidina y ultraestructura. Morfo Norm Patol 1980; 4: 13-24.

31. Frank RN, Dutta S, Frank SE. Cerebral cortical capillary basement membrane thickening in galactosaemic rats. Diabetologia 1987; 30: 739-744.

32. Frontczak-Baniewicz M. Focal ischemia in the cerebral cortex has an effect on the neurohypophysis. I. Ultrastructural chang es in capillary vessels of the neurohypophysis after focal ischemia of the cerebral cortex. Neuro Endocrinol Lett 2001; 22 81-86.

33. Fujita M, Khaznzon NM, Bose S, Sekiguchi K, Sasaki T, Carter WG, Ljubimov AV, Black K, Ljubimova JY. Overexpression of beta1-chain-contaning laminin in capillary basement mem branes of human breast cancer and its metastases. Breast Cancer Res 2005; 7: 411-421.

34. Garcia JH, Lossinsky AS, Nishimoto K, Klatzo I, Light-Foote Jr. W. Cerebral microvasculature in ischemia. In: Cervós-Navarro J, Betz E, Ebhardt G, Ferst R, Wullemweber R (eds.). Advances in Neurology. Vol. 20. Raven Press, New York 1978; pp. 141-148.

35. Garcia JH, Ben-David E, Conger KA, Geer JC, Hollander W. Arterial hypertension injures brain capillaries. Definition of the lesions. Possible pathogenesis. Stroke 1981; 12: 410-413.

36. Gazendam J, Houthoff HJ, Huitema S, Go KG. Cerebral edema formation and blood brain barrier impairment by intraventricu lar collagenase infusion. In: Go KG, Baethmann A (eds.). Recent Progress in the Study and Therapy of Brain Edema. Plenum Press, New York 1982; pp. 45-54.

37. Hall BV. Renal glomerular basement membrane as a macromolecular system forming a complex multiple random-slit mem brane filter. Anat Rec 1965; 151: 356-357.

38. Hoda MN, Singh I, Singh AK, Khan M. Reduction of lipoxidative load by secretory phospholipase A2 inhibition protects against neurovascular injury following experimental stroke in rat. J Neuroinflammation 2009; 13: 6-21.

39. Inoue S. Basement membrane and beta amyloid fibrillogenesis in Alzheimer's disease. Int Rev Cytol 2001; 210: 121-161.

40. Inoue S, Kisilevsky R. Beta-amyloid fibrils of Alzheimer's dis ease: pathologically altered, basement membrane-associated microfibrils? Ital J Anat Embryol 2001; 106: 93-102.

41. Johnson PC, Brendel K, Meezan E. Human diabetic perineural cell basement membrane thickening. Lab Invest 1981; 44: 265 270

42. Johnson PC, Brendel K, Meezan E. Thickened cerebral cortical capillary basement membranes in diabetics. Arch Pathol Lab Med 1982; 106: 214-217.

43. Junker U, Jaggi C, Bestetti G, Rossi GL. Basement membrane of hypothalamus and cortex capillaries from normotensive and spontaneously hypertensive rats with streptozoticin-induced diabetes. Acta Neuropathol 1985; 65: 202-208.

44. Kamiryo T, López MB, Kassell NF, Steiner L, Lee KS. Radiosurgery-induced microvascular alterations precede necrosis of the brain neuropil. Neurosurgery 2001; 49: 409-414.
45. Kefalides NA, Alpert R, Clark CH. Biochemistry and metabolism of basement membrane. Int Rev Cytol 1979; 61: 167-228.

46. Kilo C, Vogler N, Williamson JR. Muscle capillary basement membrane changes related to aging and to diabetes mellitus. Diabetes 1972; 21: 881-889.

47. Kiser JL, Kending JH. Intracranial suppuration. J Neursurg 1963; 20: 494-511.

48. Lampert P, Carpenter S. Electron microscopic studies on the vascular permeability and the mechanism of demyelination in experimental allergic encephalomyelitis. J Neuropathol Exp Neurol 1965; 24: 11-24.

49. Laursen H, Diemer NH. Capillary size, density and ultrastructure in brain of rats with urease-induced hyperammonaemia. Acta Neurol Scand 1980; 62: 103-115.

50. Lazarow A, Speidel E. The chemical composition of glomerular basement membrane and its relation to the production of diabetic complications. In: Siperstein MD, Colwell AR, Meyer K (eds.). Small Blood Vessel Involvement in Diabetes Mellitus. American Institute of Biological Sciences, Washington 1966; pp. 195-198.

51. Li C, Zhang WF, Zhao YF. Pericytes may have important role in the pathogenesis of vascular malformation. Med Hypothesis 2007; 68: 808-810.

52. Long DM. Microvascular changes in cold injury edema. In: Go KG, Baethmann A (eds.). Recent Progress in Study and Therapy of Brain Edema. Plenum Press, New York 1982; pp. 45-54.

53. Long DM, Hartman JF, French L. The ultrastructure of human cerebral edema. J Neuropathol Exp Neurol 1966; 25: 373-395.

54. Longhurst J, Capone RJ, Selis R. Evaluation of skeletal muscle capillary basement membrane thickness in congestive heart failure. Chest 1975; 67: 195-198.

55. Luse SA, McDougal D. Electron microscopic observations on allergic encephalomyelitis in the rabbit. J Exp Med 1960; 112: 735-742.

56. Makhamov KE, Baíbekov IM. Ultrastructure of the hematoencephalic barrier in subarachnoid hemorrhage and effect of phenobarbital. Zh Vopr Neirokhir Im N N Burdenko 2001; 1: 19-22.

57. Mancardi GL. Thickening of the basement membrane of cortical capillaries in Alzheimer's disease. Acta Neuropathol (Berl) 1980; 49: 79-83.

58. Manz HJ, Robertson DM. Vascular permeability to horseradish peroxidase in brainstem lesions of thiamine deficient rats. Am J Pathol 1972; 66: 565-575.

59. Matikainen E, Leinonen $H$, Juntunen J. Capillary morphology and muscle blood flow in diabetic neuropathy. Eur Neurol 1982; 21: 22-28.

60. McDonald LW, Hayes L. The role of capillaries in the pathogenesis of delayed radionecrosis of brain. Am J Pathol 1967; 50: 745-764.

61. McLone DG. Ultrastructure of the vasculature of central nervous system of childhood. Child's Brain 1980; 6: 242-252.

62. Meyrick B, Reid L. Endothelial and subintimal changes in rat hilar pulmonary artery during recovery from hypoxia. Lab Invest 1980; 42: 603-615.

63. Mori S, Leblond CP. Identification of microglia in light and electron microscopy. J Comp Neurol 1969; 135: 57-80. 
64. Nagata M. Age related thickening of retinal capillary basement membranes. Invest Ophthalmol Vis Sci 1986; 27: 437-440.

65. Pease DC. Polysaccharides associated with the exterior surface of epithelial cells: kidney, intestine, brain. J Ultrastruct Res 1966; 15: 555-558.

66. Persson L, Rosengren L. Increased blood-brain barrier permeability around cerebral stab wounds aggravated by acute ethanol intoxication. Acta Neurol Scand 1977; 56: 7-16.

67. Plesea IE, Camenita A, Georgescu CC, Enache SD, Zaharia B, Georgescu CV, Tenovici M. Study of cerebral vascular structures in hypertensive intracerebral haemorrhage. Rom J Morphol Embryol 2005; 46: 249-256.

68. Perimutter LS, Choi HC. Microgliopathy, the vascular basement membrane and Alzheimer's disease: a review. Brain Res Bull 1990; 24: 677-686.

69. Perimutter LS. Microvascular pathology and vascular basement membrane components in Alzheimer's disease. Mol Neurobiol 1994; 9: 33-40

70. Reese TS, Karnovsky MJ. Fine structural localization of a bloodbrain barrier to exogenous peroxidase. J Cell Biol 1967; 34: 207 217.

71. Rumpelt HJ. Hereditary nephropathy (Alport's syndrome): spectrum and development of glomerular lesions. In: Pathology of Glomerular Disease. Rosen S (ed.). Churchill Livingstone, New York 1983; pp. 225-238.

72. Salloway S, Gur T, Berzin T, Tavares R, Zipser B, Correia S, Hovanesian V, Fallon J, Kuo-Leblanc V, Glass D, Hulette C, Rosenberg C, Vitek M, Stopa E. Effect of APOE genotype on microvascular basement membrane in Alzheimer's disease. J Neurol Sci 2002; 204: 183-187.

73. Schwink A, Wetzstein R. Die Kapillaren im Subcommissuralorgan der Ratte. Elektronenmikroskopische Untersuchungen an Tierren verschiedenen Lebensalters. Z Zellforsch Mikrosk Anat 1966; 73: 56-88.

74. Scheibel AB, Duong TH, Jacobs R. Alzheimer's disease as a capillary dementia. Ann Med 1989; 21: 103-107.

75. Sehba FA, Mostafa G, Knopman J, Friedrich V Jr, Bederson JB. Acute alterations in microvascular basal lamina after subarachnoid hemorrhage. J Neurosurg 2004; 101: 633-640.

76. Schöller K, Trinkl A, Klopotowski M, Thal SC, Plesnila N, Trabold R, Hamann GF, Schmid-Elsaesser R, Zausinger S. Characterization of microvascular basal lamina damage and blood-brain barrier dysfunction following subarachnoid hemorrhage in rats. Brain Res 2007; 1142: 237-246.

77. Spiro RG. Biochemistry of basement membranes. In: Balazs EA (ed.). Chemistry and Molecular Biology of the Intracellular Matrix. Vol. I. Academic Press, New York 1970; pp. 511-534.

78. Tani E, Evans JP. Electron microscope studies of cerebral swelling. II. Alterations of myelinated fibers. Acta Neuropathol (Berl) 1965; 4: 604-623.

79. Torack RM. Ultrastructure of capillary reaction to brain tumors. Arch Neurol 1961; 5: 86-98.

80. Toti P, Villanova M, De Felice C, Megha T, Bartolommei S, Tosi P. Expression of laminin 1 and 2 in brain tumor vessels. An immu nohistochemical study. I Submicrosc Cytol Pathol 1998; 30: 227-230.
81. Uranova NA, Zimina IS, Vikhreva OV, Krukov NO, Rachmanova VI, Orlovskaya DD. Ultrastructural damage of capillaries in the neocortex in schizophrenia. World J Biol Psychiatry 2010; 11: 567-578.

82. Vise WN, Liss L, Yashow D, Hunt WE. Astrocytic process: a route between vessels and neurons following brain barrier injury. J Neuropathol Exp Neurol 1975; 34: 324-334.

83. Vorbrodt AW, Dobrogowska DH, Lossinsky AS, Wisniewski HM. Changes in the distribution of anionic sites in brain microblood vessels with an without amyloid deposits in scrapie-infected mice. Acta Neuropathol 1990; 79: 355-363.

84. Vracko R, Benditt EP. Capillary basal lamina thickening. Its relation to endothelial cell death and replacement. J Cell Biol 1970; 47: 281-285.

85. Vracko R. Basal lamina scaffold anatomy and significance for maintenance of orderly tissue structure. Am J Pathol 1974; 77 : 314-346.

86. Wang CX, Shuaib A. Critical role of microvasculature basal lamina in ischemic brain injury. Prog Neurobiol 2007; 83: 140-148.

87. Walski M, Celary-Waiska R, Borowicz J. The perivascular fibrotic reaction in rat brain in the late period after experimental clinical death. II. Precapillary vessels. J Hirnforsch 1993; 34: 503-515.

88. Walski M, Gajkowska B. The changes in the ultrastructure of the cerebrovascular junction after traumatic injury of the cerebral cortex in rats. Neuro Endocrinol Lett 2001; 22: 19-26.

89. Ward JD, Hartfield G, Becker DP, Loving ET. Endothelial fenestrations and other vascular alterations in primary melanoma of the central nervous system. Cancer 1974; 34: 1982-1991.

90. Warth A, Kröger S, Wolburg H. Redistribution of aquaporin-4 in human gioblastoma correlates with loss of agrin immunoreactivity from brain capillary basal laminae. Acta Neuropathol 2004; 107: 311-318.

91. Wechsler W, Riverson E, Schroder JM, Kleihues P, Parmeiro JF, Hossman KA. Electron microscopic observations on different models of acute experimental brain edema. In: Klatzo I, Seitelberger $\mathrm{F}$ (eds.). Brain Edema. Springer-Verlag, New York 1967; pp. 598-614.

92. Yoshida Y, Yamada M, Wakabayashi K, ljuta F, Kumanishi T. Endothelial basement membrane and seamless-type endothelium in the repair process of cerebral infarction in rats. Virchows Arch A Pathol Anat Histopathol 1989; 414: 385-392.

93. Zarow C, Baron E, Chi HC, Perimutter LS. Vascular basement membrane pathology and Alzheimer's disease. Ann N Y Acad Sci 1997; 826: 147-160. 